\title{
Evaluation of a medical program: The students' perspective
}

\author{
(iD) Mariana Contiero San Martini' \\ (iD Carla Cristina Souza Gomez ${ }^{1}$ \\ (iD) Natasha Yumi Matsunaga ${ }^{1}$ \\ (iD) Maria Ângela Reis de Góes Monteiro Antonio ${ }^{1,2}$ \\ (iD) Mariana Porto Zambon ${ }^{\mathbf{1}, 2}$
}

1. University of Campinas (Unicamp), Campinas, SP, Brasil 2. Department of Pediatrics of the School of Medical Sciences (FCM) at Campinas, SP, Brasil

http://dx.doi.org/10.1590/1806-9282.65.6.740

KEYWORDS: Health Education. Education, Medical. Faculty, Medical.

Medical education has been undergoing changes with the replacement of the traditional model for innovative education. The teacher, whose role used to be the specialist on the subject, is now a mediator/ facilitator of the student's knowledge, who in turn need to have a more active approach then being mere observers ${ }^{\mathbf{1}, 2}$.

In view of these changes, it is important that the whole process, including the assessment in relation to the faculty, is reviewed and be adequate. This assessment must be able to demonstrate the perception of students and check globally the positive and negative aspects students encounter in education. These ratings allow fundamental knowledge for future planning and institutional actions.

There several assessment tools available. For the assessment of the paediatrics course, targeted at students of the 5th year of the Medicine Program of the Faculty of Medical Sciences (FCM) of the State
University of Campinas (Unicamp), a structured questionnaire was developed, previously prepared by the coordination of the discipline and students of the Teaching Internship Program (PED), part of the graduate program of FCM-Unicamp, to be answered by the students at the end of the discipline. The questionnaire comprised questions referring to the level of satisfaction in relation to the discipline, workload, content, schedule, tests, supervision of activities, classes, and faculty. In relation to the level of satisfaction, the evaluation presented a scale of 1 to 10 , with a score of 1 to 4 indicating a poor level of satisfaction, 5 to 8 , average, and 9 or 10 , excellent. As to the questions on the appropriate workload, repetitive or advanced content, completion of the program, consistent tests, and supervision of practical activities and shifts, the students could answer yes, no, or partially. Finally, the ratings on the theoretical lessons and the supervision of each faculty mem- 
ber in practical activities were scored from zero to 10 , with zero indicating that the class or the teacher were considered terrible, 1 and 2 poor, 3 and 4 regular, 5 and 6 good, 7 and 8 great, 9 and 10 excellent. After 18 months, each teacher involved in the module received their feedback. This contained the individual assessment blindly compared to their peers. Subsequently, the grades of each teacher were compared between the pre- and post-feedback assessments to identify some characteristics linked to the teacher figure, especially those related to their didactics performance with students.

Based on the 1,140 questionnaires, we found that the discipline was evaluated satisfactorily on both moments and that, after the feedback, there was a statistically significant improvement in relation to theoretical classes, practices, skills with a dummy and, mainly, in the shift activities. The data is compatible with those found by Lieff et al. ${ }^{3}$ in 2012, who concluded that the commitment and motivation of the faculty are factors that could influence the success of the student.

Our study demonstrated the importance of students' opinions concerning the discipline of pediatrics, anonymously, showing that there are increasing concern and demand of students on the quality of the teaching, with critical sense demonstrated in the assessments.
The assessment process considers indispensable the student/teacher interaction in the teaching-learning relationship. We emphasize that discipline evaluation when well conducted, reflect the impact of the educational process through the thinking and actions of students/teachers. Some characteristics linked to the teacher figure, especially those related to their didactics performance with students were widely considered.

We believe that student satisfaction can be related to how motivated the teacher is about teaching, and other studies have shown that students can be motivated by their teachers. These authors highlighted the importance of supporting teachers through faculty development programs (including the development of competencies), which support the sense of autonomy and help to build intrinsic motivation ${ }^{4-6}$. In our opinion, the assessment tool used was a facilitator for the students to express themselves and identify the positive and negative areas in the discipline, as well as to provide an improvement in teacher performance after the feedback.

\section{ACKNOWLEDGMENTS}

We thank the Teacher Internship Programme for the work carried out and the Writing Space/General Coordinator of Unicamp for the initial translation of the article.

\section{REFERENCES}

1. Menezes FA. A avaliação dos estudantes: entre a indução da aprendizagem e a avaliação das intervenções educacionais. Cad ABEM. 2009;5:34-41.

2. Costa NMSC. Docência no ensino médico: por que é tão difícil mudar? Rev Bras Educ Med. 2007;31(1):21-30.

3. Lieff S, Baker L, Mori B, Egan-Lee E, Chin K, Reeves S. Who am I? Key influences on the formation of academic identity within a faculty development program. Med Teach. 2012;34(3):e208-15.
4. Kusurkar RA, Ten Cate T], van Asperen M, Croiset G. Motivation as an independent and a dependent variable in medical education: a review of the literature. Med Teach. 2011;33(5):242-62

5. McLeod PJ, Steinert $Y$, Meagher T, McLeod A. The ABCs of pedagogy for clinical teachers. Med Educ. 2003;37(7):638-44.

6. Stern DT, Williams BC, Gill A, Gruppen LD, Woolliscroft JO, Grum CM. Is there a relationship between attending physicians' and residents' teaching skills and students' examination scores? Acad Med. 2000;75(11):1144-6. 